\title{
La resistencia de lo silenciado en la literatura fantástica argentina
}

\author{
ANDREa CASTRO*
}

Resumen:

Dentro de un contexto intelectual que intenta exponer un "blanqueamiento" de la población en la Argentina, este trabajo tematiza la cuestión de la identidad nacional argentina desde el punto de vista de la elite intelectual situada en Buenos Aires y enfatizada por la presencia de un recurso de ambigüedad de lo fantástico: el juego con los fantasmas de cada sociedad, con aquello que cada sociedad quisiera ocultar, silenciar, "hacer ausente", pero no puede. Basado en la idea de "frontera" y en "la cuestión del indio" -figura problemática para una sociedad que se percibe europea-, el trabajo borda sobre el establecimiento de límites que separan el discurso entre el territorio de un "nosotros" y el de un "ellos", que se convierte lo mismo en un "ellos" salvaje y ominoso que amenaza la imagen que los argentinos tienen de sí mismos.

Palabras clave:

Silencios en el texto, fantástico, fronteras, identidad nacional, literatura argentina.

* Göteborgs Universitet. 


\section{Lo "hecho ausente"}

El proyecto liberal del siglo XIx de blanqueamiento de la población en lo que más tarde sería la República Argentina puede considerarse un éxito casi rotundo, por lo menos en lo discursivo. ${ }^{1}$ No porque no haya indígenas en la Argentina de hoy, que sí los hay; sino porque los argentinos, al menos hasta hace unas décadas, seguían convencidos de que ellos, a diferencia de sus vecinos y demás habitantes de Latinoamérica, eran europeos en tierras americanas. La creación de esta idea tiene sus raíces en el período fundacional del siglo XIX y es una idea que reaparece de modos diversos a lo largo de la historia de la literatura Argentina (véase Rotker).

Dentro de este contexto me interesa reflexionar acerca de ciertas presencias y ausencias en la literatura fantástica argentina, justamente por ese carácter del género fantástico de jugar con los fantasmas de cada sociedad, con aquello que cada sociedad, como apunta Jackson (4), quisiera ocultar, silenciar, "hacer ausente", pero no puede. ${ }^{2}$ Específicamente, busco estudiar la manera en la que el género fantástico tematiza la cuestión de la identidad nacional desde el punto de vista de la elite intelectual situada en Buenos Aires. Creo que la preocupación por construir y cuidar una homogeneidad racial e ideológica que tiene sus inicios en el establecimiento y desarrollo del proyecto de nación Argentina, va a seguir teniendo repercusiones sociales durante todo el siglo xx y formará parte del imaginario de las elites sobre todo porteñas. Quiero proponer que la idea de "frontera", esa necesidad de establecer límites entre el territorio de un "nosotros" y el de unos "ellos" seguirá cobrando

${ }^{1}$ Aquí me estoy refiriendo a diversos tipos de textos como discursos políticos, informes de la situación, testimonios y relatos de soldados, y textos literarios del siglo XIX que construyen las ideas de "salvaje", "frontera", "desierto", "nación blanca”, y otras relacionadas con el objetivo de conformar una nación homogénea y "civilizada". Véanse, por ejemplo, Viñas, Rotker, Andermann.

2 "The fantastic traces the unsaid and the unseen of culture: that which has been silenced, made invisible, covered over and made 'absent' " (Jackson 4). 
forma literaria en los textos fantásticos de fines del xIx y principios del xx, e incluso en otros más tardíos, mediante motivos clásicos del género. Pero también, quiero proponer que el hecho insólito propio del género que nos atañe, puede entenderse en muchos de los casos como la irrupción de los fantasmas de aquello que ha querido ser silenciado y borrado de la Historia argentina. ${ }^{3}$ Estoy pensando específicamente en lo indígena y en el "desierto", ambos sinónimos de lo que los liberales del siglo XIX denominaron barbarie y que entendieron como una de sus tareas más serias el combatir.

En este trabajo quiero estudiar de qué manera estas líneas ideológicas que inauguran lo que hoy conocemos como Argentina se instalan, a modo de constante, en la literatura fantástica, por ser ésta una literatura que de alguna forma transforma en "fantasmas" (y aquí uso "fantasmas" en sentido metafórico) aquello oculto, silenciado, prohibido en cada cultura.

Por supuesto hay otras líneas posibles en lo que respecta a los fantasmas, se podría estudiar cualquier tipo de amenaza al orden establecido en cada momento: a principios del siglo xx se podría hablar de la clase obrera en formación, las nuevas agrupaciones políticas de izquierda, las huelgas y demás. Aquí, sin embargo, elijo concentrarme en este hecho fundacional que fue la eliminación y asimilación de las poblaciones indígenas que habitaban un suelo que no era un desierto -si no se entiende desierto como lugar despoblado de personas de origen criollo o europeo-, un hecho que constituye una base sobre la que descansa lo que hoy es la nación Argentina. No es posible que semejante hecho quede en el olvido, por más intentos discursivos que se hayan hecho por borrarlo, justificarlo o disminuir su importancia.

¿De qué manera aparecen tematizados el "desierto", y las poblaciones indígenas que éste albergaba, en la literatura fantástica ar-

3 "El mito de origen argentino instaura un Fantasma producido a partir de la negación y la eliminación de sociedades y culturas, calificadas como no-sociedad y como no-cultura, y su sustitución utópica por La Sociedad y La Cultura generadas desde la clase dirigente enajenada en los modelos europeo y norteamericano. Negación y afirmación, vaciamiento y trasplante son movimientos complementarios dentro de nuestras historia”. (Perilli 15) 
gentina? ${ }^{4}$ ¿Qué formas adquiere el clásico binomio civilización y barbarie, en el cual el "desierto" y "los salvajes" 5 son parte constitutiva de esta última? ¿Cómo se hacen sentir los fantasmas de aquello "hecho ausente"?

A primera vista pareciera que no hay desierto ni indígenas, que la idea de nación homogénea (Quijada) es tan compacta que estos ni siquiera aparecen disfrazados de fantasmas. Esto aún más cuando se compara la literatura fantástica argentina con la mexicana, con sus Chac Mools y sus tlaxcaltecas, ${ }^{6}$ por poner los ejemplos más obvios. O si se piensa en que cuando, por ejemplo, Cortázar crea personajes, ya sea individuales o grupales indios, éstos se sitúan en otras tierras o aluden a las culturas indígenas del norte de Latinoamérica en lugar de a las del territorio argentino. ${ }^{7}$

Campra, refiriéndose a los silencios del texto en la literatura fantástica apunta que: "el silencio recubre un problema más vasto que, sin negarlo, lo trasciende, y es el de la imposibilidad de reconocer la

4 “Entre esos territorios y los ocupados por la sociedad mayoritaria se extendía lo que en la época era conocido como 'fronteras interiores', la más importante de las cuales era una línea imaginaria horizontal que -de este a oeste-iba aproximadamente desde el sur de la provincia de Mendoza hasta el océano Atlántico, y que aislaba a la Patagonia y parte de las pampas de los territorios del norte. Al sur de esa línea se extendía el 'desierto', eufemismo que simbolizaba la ausencia o escasez de asentamientos 'blancos' y el rechazo de la sociedad mayoritaria a conceder a los grupos indígenas que lo habitaban el carácter y estatus de 'poblaciones'. Una segunda 'frontera interior', situada al noreste, circundaba la zona del Chaco, reducto de grupos indígenas que consiguieron mantener su autonomía hasta comienzos del siglo xx". (Quijada 59-60)

${ }^{5}$ Dice Sarmiento: “El mal que aqueja a la República Argentina es su extensión: el desierto la rodea por todas partes, y se le insinúa en las entrañas; la soledad, el despoblado sin una habitación humana [...] la inmensidad por todas partes: inmensa la llanura, inmensos bosques, inmensos los ríos, el horizonte siempre incierto [...] Al sur y al norte, acéchanla los salvajes, que aguardan las noches de luna para caer, cual enjambre de hienas, sobre los ganados que pacen en los campos y sobre las indefensas poblaciones." (67-68, mis negritas)

${ }^{6}$ Me refiero a los cuentos "Chac Mool" de Carlos Fuentes (Los días enmascarados, 1954) y "La culpa es de los tlaxcaltecas" de Elena Garro (La semana de colores, 1964).

7 Estoy pensando en "La noche boca arriba", "Apocalipsis de Solentiname" y "Axólotl”, por ejemplo. 
palabra del 'otro’. Más aún, si éste representa una otredad absoluta, como es el caso de la criatura fantástica.” (57-58)

En este trabajo, me interesan los silencios que representan la otredad, no tanto de "la criatura fantástica", al decir de Campra, como de aquello que fue negado, silenciado, borrado de la Historia por un proyecto de nación que se inicia en el siglo xix y que todavía tiene consecuencias en lo que es hoy la comunidad imaginada (Anderson 1991) que es Argentina.

Después de estudiar en tres cuentos claramente fantásticos de qué manera lo silenciado se resiste a su condición de tal, voy a detenerme en un cuento que me permitirá ilustrar que, todavía en pleno siglo xx, la identidad indígena, como amenaza a la idea de nación homogénea, puede jugar un papel definitorio en la clasificación de un texto como fantástico.

\section{Casas como castillos góticos}

Para abordar la cuestión de la otredad, el espacio narrativo de la casa como transformación de un motivo típico del género fantástico nos puede ser útil. Se trata del motivo del castillo gótico, un motivo clásico que persiste gracias a su capacidad de transformación y adaptación. ${ }^{8}$ Encuentro especialmente interesante la coexistencia de tiempos que este motivo posibilita en un espacio narrativo delimitado. Por un lado, está el tiempo histórico que impregna las paredes con cuadros y tapices y los muebles que han sido tocados y usados por otras generaciones; por otro, está el presente de la historia narrada.

Además, el motivo lleva el componente del aislamiento. El castillo gótico se encuentra en un paraje aislado, separado del resto del mundo y sólo algunos -los elegidos- pueden llegar y ser admitidos.

\footnotetext{
${ }^{8}$ Bajtin (396) señala que el castillo, a partir de Walpole, es un "nuevo territorio de desarrollo de los acontecimientos novelescos" y que la temática del castillo tiene que ver con el tiempo histórico presente en su interior. (Ver también Castro 125-126.)
} 
En general el protagonista debe atravesar ciertos obstáculos antes de llegar a su interior.

Pero asimismo, el castillo es una construcción con paredes gruesas que definen claramente un adentro y un afuera. Esta frontera materializada y solidificada en un muro y en una o más puertas, pasa a formar una expresión material del límite entre lo que se incluye como deseado y lo que se excluye como indeseado. Se puede interpretar ese interior claramente delimitado, ya no por una frontera fluida y porosa, sino por una rígida y sólida, como un intento de establecer un centro, de encapsular la Historia en un afán homogeneizador.

Veremos en los textos que nos ocupan que estas casas/castillo se erigen como monumentos de civilización en un territorio por lo demás precario o amenazante. Son casas que si bien parecen contener una versión del pasado, verán dentro suyo el despertar de lo que Freud ha llamado lo Unheimliche, lo que no cuadra por no ser familiar, lo que ha sido reprimido, lo que "estando destinado a permanecer en secreto, en lo oculto, ha salido a la luz" (225).

\section{La sombra escandalosa en "Un fenómeno inexplicable" (1906)}

En "Un fenómeno inexplicable" un narrador autodiegético rememora una visita que hizo a la zona de la llanura pampeana entre Córdoba y Santa Fe. ${ }^{10}$ Para evitar dormir en una de "las horribles posadas de aquellas colonias en formación” (Lugones 75), el narrador obtiene una carta de un juez de paz que le ha de servir de

9 "Un fenómeno inexplicable" fue publicado por primera vez bajo el título de "La licantropía" en la revista de la sociedad teosófica argentina Philadelphia, en septiembre de 1898. Luego fue levemente modificado y, con el título con el que lo conocemos hoy, fue publicado en Las fuerzas extrañas por la editorial Arnoldo Moen y Hermano en 1906.

10 "Los departamentos del sur de Córdoba, así como las tierras del centro de Buenos Aires y la franja sur de Santa Fe eran también un espacio de antiguo 
presentación ante un inglés muy reservado que vive en "una casa, lo mejor de la colonia" (75).

El paisaje se describe desprovisto de todo aquello que podría relacionarse con la "barbarie", con lo "salvaje", por ejemplo, casitas, parvas, tierra cultivada: "A raíz del terraplén, la pampa con su color amarillento como un pañuelo de yerbas; casitas sin revoque diseminadas a lo lejos, cada una con su parva al costado; sobre el horizonte el festón de humo del tren en marcha, y un silencio de pacífica enormidad entonando el color rural del paisaje." (76)

Todo el pasaje que describe la casa invoca la idea del motivo del castillo gótico. Es cierto que no se describe como totalmente aislada, ya que se encuentra a unas diez cuadras de la estación, pero el narrador no deja de mencionar que se llega a ella por "un camino polvoroso" (76), y luego la describe como destacando por "cierta gallardía exótica entre las viviendas circundantes". También señala que el patio estaba rodeado por una pared y que, a pesar de ser agradable a la vista, parecía deshabitada. Es más, por el silencio que la rodea, el narrador la compara con un sepulcro en un "antiguo cementerio" (76), señalando asimismo que el jardín está descuidado y crece libremente. Este último detalle cobra importancia en contraposición al paisaje cuidado que rodea el cerco de la casa, constituyéndose así como una amenaza, prolepsis de lo salvaje que surgirá del lado de adentro.

$\mathrm{Al}$ presentarse en la casa del inglés, el narrador es recibido gracias a la carta de la que es portador. Así ingresará en un ámbito cerrado, en el cual el inglés ha vivido solo desde la muerte de su mujer ocho años atrás. En este espacio cerrado, el inglés revelará su secreto: tras años de experimentar con la traslación consciente, se ha desdoblado irremediablemente y adonde quiera que vaya, lo sigue la sombra de un mono, que viene a ser algo como su otro yo, su

poblamiento representando el límite del mundo 'civilizado'. Esta zona -principalmente los departamentos del centro y norte de Córdoba- había accedido durante siglos a los principales mercados por vía de carretas hasta la boca natural del río Paraná" (Zeberio 324). 
otra cara. El narrador, escéptico, diseña un experimento para probar que el inglés es presa de su imaginación, pero este mismo experimento lo dejará totalmente perplejo. Si bien a simple vista no es obvio, el perfil del inglés, proyectado como sombra en la pared, es el perfil de un mono.

Hay varios paralelos con Dr. Jekyll and Mr. Hyde (1886), tanto en los temas principales del cuento como en el modo de narrar en algunos pasajes, pero el cuento de Lugones plantea nuevos temas que tienen que ver con el contexto sociocultural en el cual se ubica. Al igual que en el cuento de Stevenson están presentes el tema fáustico y el tema del doble, temas, por lo demás, clásicos del género. Sin embargo, un tema que hace este cuento especialmente relevante para este trabajo es justamente el tema de la civilización y la barbarie, el tema de la otredad bárbara.

Lugones elige como escenario de su cuento la zona de la llamada pampa gringa (Hourcade), una zona de colonos ingleses, desprovista de la amenaza de los "salvajes", como los llamaría Sarmiento, el ideólogo del proyecto de nación más influyente en la Argentina del siglo XIX.

El inglés es un colono, uno de aquellos habitantes europeos invitados a poblar el llamado desierto en una zona de la llanura pampeana ganada a los "indios". Tan tarde como en 1904, los mocovíes atacan una localidad en el norte de la provincia de Santa Fe. ${ }^{11}$ O sea que la llamada "cuestión del indio" está todavía muy candente en la Argentina de principios de siglo.

Podemos así entender el personaje del inglés como ocupando el polo "civilización" en el binomio civilización/barbarie. Su casa, ese "chalet industrioso" "con su parapeto y su cornisa" (76) refuerza esta idea de civilización. Es más, como una variación del motivo

11 “Los departamentos del sur de Córdoba, así como las tierras del centro de Buenos Aires y la franja sur de Santa Fe eran también un espacio de antiguo poblamiento representando el límite del mundo "civilizado". Esta zona -principalmente los departamentos del centro y norte de Córdoba- había accedido durante siglos a los principales mercados por vía de carretas hasta la boca natural del río Paraná" (Zeberio 324). 
del castillo gótico, la casa se constituye como un centro casi diría infranqueable de civilización. No obstante, esa civilización aparece como amenazada por lo salvaje, materializado por el jardín que crece libremente.

En el interior de la casa, tras la fachada industriosa de la casa, y tras la fachada "blanca" del inglés - "cabeza elevada y calva [...], nariz austera $[. .$.$] protuberancias superciliares" y mentón marcado$ (76-77) - surge la sombra del mono con "una frente deprimida, una nariz chata, un hocico bestial" (83). De este modo el hecho insólito, al irrumpir en un sistema aparentemente cerrado, es escandaloso. El inglés y su casa contienen al mono; la civilización contiene la barbarie. Desde esta perspectiva, la comparación que al principio del cuento se establece entre la casa y un "sepulcro nuevo en el emplazamiento de un antiguo cementerio" (76), adquiere tonalidades más oscuras, ya que se puede entender la tierra sobre la que descansa como una tierra antes poblada por otra civilización que ha sido enterrada para dar lugar a los nuevos pobladores.

\section{La ansiedad por lo europeo en Borderland (1907)}

Borderland, de Atilio Chiáppori, es un libro de cuentos compuesto a modo de relato marco con siete relatos enmarcados. El relato marco tiene lugar en una quinta llamada Las Glicinas, en la cual un personaje que conocemos como "La interlocutora" recibe al narrador durante un otoño para que éste le cuente historias trágicas de amigos y conocidos en común o parientes de ellos. Según palabras del narrador sabemos que cuando la interlocutora intuye que éste está "a punto de adivinar su secreto" (Chiáppori 19), le cierra las puertas de Las Glicinas y se aísla a escribir en "un suntuoso cuaderno de cantos dorados" (19).

El relato marco se ve, entonces, contenido dentro de los límites del jardín de la quinta por el cual pasean a veces, mientras el narrador cuenta la historia de turno. Pero todos los encuentros terminan en el "salón de reliquia, donde había siempre una partitura olvidada en el historiado facistol y grandes rosas exangües en los floreros 
antiguos" (20). Un salón cargado de los atributos del castillo gótico: muebles antiguos y retratos de los antepasados; un salón en el cual se abre la posibilidad de la coexistencia de tiempos pasados y el tiempo presente de la narración. No obstante, este salón, al igual que el diálogo que se desarrolla en él entre narrador e interlocutora, incluye un solo tipo de pasado, un pasado que sirve para construir la imagen de sociedad con fuertes raíces europeas. Se percibe en la descripción una cierta ansiedad por encerrar el mundo "correcto" dentro de la quinta y dentro del relato: una ansiedad por lo europeo.

Esta ansiedad por lo europeo se percibe también en la profusión de referencias a personajes, escritores y artistas provenientes de la cultura europea y anglosajona, la cultura “occidental". Ya en la primera página se nombran a Radiana Glanegg, la pintora Kate Greenaway, y los personajes poeianos de Morella y Ligeia. Además, a lo largo de todo el libro, hay pocos personajes que no pertenezcan a ese pequeño mundo de amigos y conocidos en común. Así, narrador e interlocutora, al definir el ambiente y el mundo interior de la casa y del relato, ansiosamente construyen una realidad que se diferencia de la naturaleza que rodea a la quinta. Esa naturaleza que es América y no Europa, que es "barbarie" en contraposición a la "civilización” que encierra Las Glicinas.

Me detendré en el primer cuento del libro, que lleva el título "Un libro imposible" y es el más largo (unas 50 páginas). En éste el narrador cuenta de su viaje a Luján, donde está la quinta de su amigo Augusto Caro que, a pesar de haber cortado todo contacto durante seis años, lo llama con urgencia a través de una carta desperada. Al llegar el narrador a la estación de Luján, se ha desatado un temporal y el andén está repleto de gente. No es difícil percibir la incomodidad de nuestro narrador en este espacio:

Como nunca, experimenté entonces esa impresión de inquietud indefinible de los arribos nocturnos. Verdad es que el aspecto trágico de las estaciones de campaña a tales horas, complicábase aquella noche con una concurrencia a la chamberga, donde la precaria luz de petróleo destacaba únicamente las cabezas, silenciosas y foscas, sobre un remolino 
de ponchos humeantes que el aguacero impelía bajo el tinglado. (26-27)

Al bajar del tren, símbolo por excelencia del progreso, el narrador se encuentra en un andén mal iluminado por una "precaria luz de petróleo". En este espacio repentinamente no moderno, el narrador se enfrenta con el Otro: el campesino, el gaucho, el inmigrante, el indio. Es especialmente significante el modo en el que describe a estos Otros, uniéndolos en una masa indiferenciada, una sombra: no hay caras, sólo cabezas; no hay cuerpos, sólo ponchos humeantes; no hay acción por parte de ellos, quién actúa es el aguacero, que impele estas cabezas y estos ponchos bajo el tinglado. Si bien es cierto que la mala iluminación no le puede permitir ver mucho más, no se puede dejar de notar que la forma de describir a la gente que hace uso de la estación los acerca más a una manada de animales sumisos que a un grupo de individuos humanos.

Todavía en la estación, pero ya en una "salita" en su interior, el hijo de Augusto, Mario, se altera mucho al ver a Pablo Lasca del lado de afuera de la ventana. Pablo Lasca es un personaje a quien todos temen, y del cual se dice que tiene poderes diabólicos. Así lo describe el narrador:

Verdaderamente, el aspecto de aquel hombre era como para inspirar recelo. Enclenque y bajo, tenía en sus actitudes esa movilidad convulsiva de los poseídos. Nadie hubiera podido precisar su edad. No obstante, las estrías profundas de las arrugas y el cabello gris, su rostro inberbe (sic), albarazado, ostentaba en los ojos pequeños y agudos un reflejo de juventud siniestra. Jurara conocerle de antaño. Recordaba confusamente aquel rostro como en esa lejanía imprecisa de las imágenes infantiles. (29)

Se dice entre otras cosas que las tres mujeres que ha tenido, murieron repentinamente en noches de tormenta a menos de medio año de casarse con él. Pablo Lasca siempre aparece fuera de la ventana, como significando los peligros que amenazan en ese exterior 
pampeano. Sin embargo, un poco más tarde el narrador identifica el rostro de Pablo Lasca como "el mismo de aquel mago de L'Incantation" (31) del pintor belga Felicien Rops, recurriendo nuevamente a esta ansiedad por lo europeo de la que hablábamos antes. Hasta para explicar lo atemorizante el narrador debe recurrir a elementos importados.

La llegada a la casa de Augusto se describe con varios elementos que aluden al motivo del castillo gótico: la lluvia, el camino de granza, una escalera que lleva a la entrada y Rosina, la mucama, con una temblorosa vela en la mano. La idea del exterior amenazante se repite una vez en el interior:

Fué a cerrar los postigos y se detuvo temblando.

-¿Qué hay

-No sé, afuera ocurre algo...

Yo sentí una onda gélida correrme en la médula y me acerqué a mirar. No se hubiera podido decir lo que pasaba afuera. [...] Aquel silencio repentino, aquella repentina inmovilidad de los árboles y del viento en medio del temporal, hacían pensar en esos momentos de estupor ambiente que preceden al de las puertas que se abren solas. (38)

Pero en realidad, donde ha ocurrido algo terrible es adentro, en esa casa en cuyo piso alto una puerta se golpea acompasadamente $(32,35)$. La mujer de Augusto, Ana María, ha muerto en condiciones inciertas. Según lo que él cuenta al narrador, su iniciativa de experimentar con la "transfusión de espíritus" para poder escribir su libro soñado, lleva finalmente a Ana María al suicidio. Pero el texto también plantea otra posible lectura: Augusto desvaría y lo que cuenta sólo ha ocurrido en el interior de su mente. Ana María ya no está, pero puede haber muerto de otro modo, o simplemente haberlo dejado. ${ }^{12}$

${ }^{12}$ Aquí aparece una variación de la figura del artista romántico, aquél que destruye a quienes ama, por su creación. Un par de modelos importantes de tratamiento de 
$\mathrm{Al}$ igual que la quinta del relato marco, la casa de Augusto Caro contiene una historia diferente a la de la geografía sobre la que está erigida, una historia europea y anglosajona. Basta con enumerar los autores que el narrador observa en la biblioteca de su amigo Augusto: "Hoffmann, Poe, Baudelaire, Walter Pater, Jules, Bois, D’Annunzio, Mœterlink, Verlaine, Samain, Sar Peladan [...] Le Dantec, Ribot, Magnan, Berheim, Crookes, Kardec, De Rochas, Pregalmini, Papus, Sage, Kraft-Ebing etcétera” (39-40).

Esta ansiedad por lo europeo, con su consecuente negación ya no sólo de lo indígena, de lo autóctono, sino de lo latinoamericano en general, de la heterogeneidad de la que es testigo esta tierra, llama poderosamente la atención. Porque si bien tanto el género como las referencias son importados, en ese afán realista/mimético del género fantástico, el autor se encarga de situar las historias en el territorio de la provincia de Buenos Aires haciendo muy evidente el proceso de selección -y por tanto de exclusión- del realismo. (En este caso: la tierra, sí; sus habitantes todos, no.) O, dicho de otro modo, la expresión de la ansiedad por lo europeo hace muy evidente el poder performativo del texto literario en tanto discurso, productor de realidad más que reflejo de la misma.

\section{Silencios ruidosos en "Casa tomada" (1946)}

Saltando cuarenta años en el tiempo, nos encontramos con otro cuento que actualiza el motivo del castillo gótico y que sin duda, guarda interesantes paralelos con los antes estudiados. Queda por analizar el lapso que separa los cuentos aquí trabajados, para así añadir otros textos a esta posible genealogía.

este motivo se encuentran en "The Prophetic Pictures" (1835) de Hawthorne y en "The Oval Portrait" (1842) de Poe. 
En "Casa tomada" $"$ se cuenta la historia de dos hermanos que viven solos en la casa que ha sido de sus antepasados, a principios de la década del 40. La casa está situada en Barrio Norte en la ciudad de Buenos Aires, barrio de palacetes y casas señoriales, que pertenecían a las familias patricias. "Nos gustaba la casa", nos dice el narrador autodiegético iniciando el relato, "porque aparte de espaciosa y antigua $[. .$.$] guardaba los recuerdos de nuestros bisabue-$ los, el abuelo paterno, nuestros padres y toda la infancia" (Cortázar 9). De este modo, queda subrayado desde un principio el hecho de que se trata de la casa de la línea paterna de la familia. Esta línea patriarcal es reforzada por el hecho de que el hermano tenga el rol de narrador y de focalizador de la historia. Todo lo que leemos nos llega filtrado por la voz, por la visión y por la forma de interpretar lo que percibe, de este narrador sin nombre.

Al mismo tiempo, a través de la descripción de la casa se actualiza el motivo del castillo gótico: ese espacio dentro de cuyas paredes coexisten los tiempos pasados y el presente de la narración.

El narrador pasará a describir la distribución de la casa y señalará que la parte más retirada de la misma daba hacia la calle Rodríguez Peña. Nicolás Rodríguez Peña fue uno de los protagonistas de la resistencia a las Invasiones inglesas en los años 1806 y 1807 y formó parte de todas las actividades de mayo del 1810. También fue miembro del Segundo Triunvirato. El hecho de que la calle que bordea el fondo de la casa lleve el nombre de semejante personaje histórico, nos permite ver la casa como una especie de flecha temporal que arranca en los albores de lo que luego será la República Argentina. Junto con la idea de que la casa pertenece a la línea patriarcal de la familia, podemos proponer la casa como la Patria, la nación Argentina.

El narrador también aclara que, siendo la casa demasiado grande para dos personas, los hermanos viven en la parte delantera de la misma, lo cual sería el presente según la interpretación de la

13 “Casa tomada" fue publicado en 1946 por Borges en la revista que éste dirigía, Los Anales de Buenos Aires, y luego incluido en Bestiario (1951). 
flecha temporal. En la parte trasera, del otro lado de un pasillo con una "maciza puerta de roble" (12), que el narrador menciona varias veces como subrayando su existencia, se encuentra "el comedor, una sala con gobelinos, la biblioteca y tres dormitorios grandes" (11). Holmes se detiene en esta insistencia del texto en cuanto a la puerta de roble y la inquietud que parece despertar en el narrador:

Instead of describing their perception of the "they", the narrator replaces the "they" by the door. The oak door represents the dual characteristics of walls identified by Peter Marcuse: both connector and divider, protector and excluder. Here, Cortázar uses this dualism in his construction of a penetrable fictional wall. (Holmes 259)

El narrador también cuenta que él y su hermana Irene sólo van a la parte que está detrás de la puerta de roble cuando tienen que hacer la limpieza. En este momento del relato pasa algo: el estilo descriptivo focalizado en el espacio particular que es la casa se enlaza con una generalización acerca de Buenos Aires, sus habitantes y un polvo insistente que prácticamente cobra vida propia:

Buenos Aires será una cuidad limpia, pero eso se lo debe a sus habitantes y no a otra cosa. Hay demasiada tierra en el aire, apenas sopla una ráfaga se palpa el polvo en los mármoles de las consolas y entre los rombos de las carpetas de macramé; da trabajo sacarlo bien con plumero, vuela y se suspende en el aire, un momento después se deposita de nuevo en los muebles y los pianos. (12-13)

¿A qué se debe la insistencia de ese polvo que obliga a los habitantes de la ciudad a vanamente empuñar plumeros? ¿Qué historia está queriendo contar? Sin duda, el polvo con su calidad casi animada introduce una tensión que servirá para la construcción de lo fantástico. El polvo cobra la forma de una presencia inquietante, algo que amenaza la meticulosidad de los habitantes de esta ciudad. 
El polvo como tal no hace ruido, pero su presencia es palpable y visible, es un polvo agresivo en su aparente pasividad.

Según lo describe el narrador, este polvo se deposita en mármoles y carpetas de macramé, en los muebles y en los pianos, todos elementos éstos que se relacionan con la burguesía, con la "civilización". En este contexto de lectura no puedo dejar de pensar en el polvo que trae la idea del "desierto", de ese "desierto" inventado por los ideólogos liberales, para poder ocuparlo y usurparlo a los fines de expandir la llamada civilización. La metáfora decimonónica del "desierto" cobra aquí materialidad y se convierte en este polvo que al depositarse en mármoles y carpetas de macramé, tapa el brillo "civilizatorio", deconstruyendo así el binomio, mostrando que la civilización se ha fraguado de hechos sombríos. La ciudad, y especialmente el barrio en el que viven los hermanos, se ha construido a partir de las riquezas que ha dado el "desierto" conquistado. El mismo narrador aclara "No necesitábamos ganarnos la vida, todos los meses llegaba la plata de los campos y el dinero aumentaba" (11). Pero el "desierto", en forma de polvo, se resiste a ser definitivamente "civilizado", depositándose constantemente en las marcas de esta civilización.

El polvo, según nos hace entender el narrador, está en todas partes, es una amenaza que viene desde afuera. En pocos renglones, nos enteraremos que en el interior de la casa de los hermanos también hay una amenaza y ésta está conformada por los ruidos que se inician en la parte posterior de la casa que, aquélla que apunta hacia Rodríguez Peña, hacia el pasado, hacia lo que sería el período de conformación de la nación. Cuando el narrador oye estos ruidos cierra la puerta de roble con llave y con cerrojo, ${ }^{14}$ dejando la parte de atrás de la casa sellada. Al abandonar esa parte de la casa a los ruidos extraños, los hermanos pierden objetos que extrañarán: los libros de literatura francesa del narrador, su pipa de enebro, las

14 “Me tiré contra la puerta antes de que fuera demasiado tarde, la cerré de golpe apoyando el cuerpo; felizmente la llave estaba puesta de nuestro lado y además corrí el gran cerrojo para más seguridad" (13). 
carpetas y las pantuflas de Irene (14). Todos éstos, al igual que aquellos elementos que el polvo insiste en cubrir, también se relacionan claramente con la "civilización", con la burguesía europeizada y europeizante de las clases patricias argentinas (y latinoamericanas). Sin embargo, como buenos fantasmas, los ruidos no dejarán que puerta de roble maciza ni "gran cerrojo" alguno los detenga; como buenos fantasmas sabrán atravesar tanto puertas como paredes.

¿Qué ruidos son éstos que llegando del pasado terminan expulsando a los hermanos de la casa/castillo que alberga la historia patriarcal de la burguesía (argentina)?

Estos primeros ruidos, junto con los que el narrador oirá más tarde, constituyen el hecho insólito en este cuento fantástico, y, debido a la potencialidad de significados de que los hechos insólitos se hacen portadores, han sido interpretados de muchas maneras por la crítica. ${ }^{15}$ Así explica Moreno Turner el paradójico silencio creado por estos ruidos:

Recordemos que el texto se construye sobre la base de elementos presentes y ausentes. Tenemos, por un lado, la presencia de la casa y de la vida de los personajes en ella, por otro, el significante de significado ausente, las fuerzas invasoras que se apoderan de la mansión. El relato gira en torno a esa ausencia, a un silencio, al silencio de lo dicho por el narrador, al silencio con respecto a los ruidos que constituyen la manifestación de los invasores. (Moreno Turner 78)

\footnotetext{
${ }^{15}$ Sosnowski se refiere a fuerza extraña o "fuerza suprarreal" pero a la vez hace referencia a la interpretación de David Viñas que ve el cuento como una alegoría al peronismo (23) y, por ende, los ruidos representarían el caos desatado por este movimiento como amenaza a la burguesía. Andreu recoge algunas interpretaciones de los años 60, que van de una concretización de los ruidos en "las rudas expresiones de alegría de la familia cabecita negra" según Sebreli (52), a interpretaciones más abiertas como el ser "potencias secretas" para Speratti Piñeiro (citado en Andreu 54), "ocupantes desconocidos (¿antepasados?)" según Hart (citado en Andreu 55), o "esos mismos innumerables recuerdos, [...] el pasado, [...] las presencias absorben-
} 
Estoy de acuerdo con Moreno Turner en cuanto a que el relato gira en torno a ausencias y silencios y en que el hecho insólito es un significante de significado ausente, un vacío en el texto que el lector es invitado a rellenar. En la propuesta de lectura que aquí presento, el silencio que me interesa es el silencio que se resiste a ser tal. No es el silencio en cuánto a la falta de explicación que se le da al hecho insólito, sino el silencio que a través de actos de resistencia se niega a ser tal. En este cuento, el silencio se materializa en forma de polvo y en forma de ruidos "sordos", o como lo formula el narrador: "El sonido venía impreciso y sordo, como un volcarse de silla sobre la alfombra o un ahogado susurro de conversación" (13). Estos ruidos pueden entenderse como la resistencia de un silencio instaurado en el imaginario de una sociedad que se construyó sobre la base de borrar a otra/s sociedad/es o cultura/s.

\section{El fantasma de la identidad en "La expiación” (1961)}

Un cuento que toma una posición particular dentro de esta genealogía es "La expiación"16 de Silvina Ocampo. Y digo particular porque si bien fue incluido en la segunda edición de la Antología de la literatura fantástica de Borges, Bioy Casares y la misma Ocampo (1965), no hay nada en el cuento, que nos permita entenderlo como fantástico. ¿Qué tiene este cuento que otros lectores ávidos del género, como lo fueron los tres compiladores de la antología, lo hayan visto como fantástico? No hay hecho sobrenatural y por ende, no

tes que nuestras propia vida crea a su alrededor" (Andreu 56). Alazraki también recoge parte de la crítica de los 60 y 70. Según Planells (600) los ruidos son creados por los antepasados de los hermanos. Pérez Venzalá plantea la hipótesis de que "invasores, que con tanta naturalidad, van expulsando a los dos hermanos de la casa, no son en realidad más que el deseo incestuoso que desde el inconsciente, identificado con la parte más profunda de esta casa-familia-psiquismo, va emergiendo hacia la superficie de la conciencia, identificada finalmente con el exterior de la casa".

${ }^{16}$ Incluido en Las invitadas (1961). 
hay conflicto alguno entre modos epistemológicamente diferentes de concebir el mundo de la historia. En este sentido, no tiene lugar en la genealogía aquí planteada.

No obstante, es justamente esta contradicción la que me lleva a incluirlo en la discusión. Ya que la única explicación a la inclusión del cuento en la mencionada antología que puedo esbozar está relacionada con la propuesta de lectura de este trabajo. Según lo entiendo, la ambigüedad planteada en el texto en cuánto a la identidad del personaje llamado Antonio cobra matices sobrenaturales o inexplicables bajo la mirada de los antologadores, denotando una postura ideológica, quizás inconsciente, pero no por eso menos potente en cuanto a las consecuencias que pueda tener. Dicho de otro modo, el tema de la otredad de Antonio es interpretado como hecho insólito por los antologadores y es éste el que los lleva a incluir al cuento en la mencionada antología. Según la postura ideológica que aparece implícita en esta lectura, un cuerpo que contenga a un criollo y a un indio no puede ser entendido de otra manera que como un desdoblamiento fantástico, si bien nada en el texto apunte a ese tipo de interpretaciones.

En el cuento una narradora autodiegética cuenta la historia de un triángulo amoroso entre ella misma, su marido Antonio, y un amigo en común de la pareja, llamado Ruperto. Ruperto visita a menudo a la pareja y poco a poco la narradora se va dando cuenta de que su mirada no es la de un simple amigo sino que la mira con deseo. Antonio también parece darse cuenta, pero no dice nada, ocupado como está amaestrando sus canarios. La historia se centra en el día que Antonio reúne a la narradora y a Ruperto (que ha quedado ciego un tiempo atrás) para mostrarles "una prueba". La prueba consiste en que los canarios toman una flecha de un recipiente y la mojan en otro recipiente con un líquido oscuro que luego resulta ser curare. Después de dar unas vueltas y cantar por la habitación, los pájaros empiezan a clavar las flechas en el torso desnudo de Antonio. Casi hacia el final de la prueba la narradora entiende que los pájaros clavarán las flechas en los ojos de Antonio "para que no pudieran mirarme, pobrecitos, nunca más" (Ocampo 
256), explica. Con esta prueba Antonio también confiesa, indirectamente, ser el responsable de la ceguera de Ruperto.

La narración se estructura a partir de los detalles de este día específico, con trozos analépticos que, insertados en letra cursiva, van dando el trasfondo de la historia: el casamiento entre la narradora y Antonio, las visitas de Ruperto y los comentarios de Cleóbula, también amiga de familia, acerca de Ruperto y de Antonio.

Esta trama, como está planteada, no presenta elementos fantásticos. No hay nada en el mundo narrado que aparezca como sobrenatural y, menos aún, que se plantee como un conflicto entre dos sistemas epistemológicamente incompatibles. Sin embargo, repito, los antólogos lo eligieron entre todos los demás cuentos que había escrito Ocampo hasta el momento, para representar el género fantástico.

A lo largo de la narración, aparece primero el tema de la otredad de Antonio en un sentido general, pero poco a poco esta otredad se irá identificando con la posible identidad indígena de este personaje. La primera vez, es la narradora misma quien expresa un pensamiento en este sentido: "No era de extrañar que Antonio me dejara de algún modo perpleja: jera tan distinto de los otros hombres!" (Ocampo 248). Más adelante, la narradora lo compara con una estatua: "Antonio silbó, se quitó la camiseta. Su torso desnudo parecía de bronce. Me estremecí al verlo. Recuerdo que antes de casarme me ruboricé ante una estatua muy parecida a él" (250). Hasta aquí, Antonio se presenta como diferente, pero sin explicar qué lo hacía diferente. Poco a poco van apareciendo otros elementos que señalan la identidad indígena de Antonio. Por un lado, la narradora cuenta de una ocasión en la que encontró un muñeco de estopa que Antonio le arrancó de las manos diciendo: "Es un recuerdo de mi infancia. [...] No me gusta que toques mis cosas" (252). El muñeco representa la infancia de Antonio, una infancia que guarda celosamente y que parece no querer compartir con su mujer, como un pasado silenciado.

Otro elemento significativo son las flechas y el curare que Antonio hace usar a los canarios y con las que finalmente se hace enceguecer: "Así son los indios: usan flechas con curare" (253), le 
dice su amiga Cleóbula a la narradora y prosigue "Se dedican a las brujerías. Tu marido es un indio" (253), comentario ante el cual la narradora reacciona con asombro.

Perdí la confianza en Cleóbula. Sin duda decía que mi marido era un indio para afligirme o para hacerme perder la confianza en él; pero al hojear un libro de historia donde había láminas con campamentos indios, e indios a caballo, con boleadoras, encontré una similitud entre Antonio y esos hombres desnudos, con plumas. Advertí que lo que me había atraído de Antonio era tal vez esa diferencia que había entre él y mis hermanos y los amigos de mis hermanos, el color bronceado de la piel, los ojos rasgados y ese aire ladino que Cleóbula mencionaba con perverso deleite. (253-254)

De este modo, la narradora finalmente atribuye ese "ser diferente" de su marido a su identidad indígena, una identidad que el propio Antonio no comenta en ningún momento, una identidad que lleva en silencio y que aflora en su trato con los pájaros y con los animales en general, mostrando en este detalle su conexión con la naturaleza, con lo salvaje: "Antonio se había dedicado, en los momentos libres, a amaestrar animales; primero usó de su arte, pues era un verdadero artista, con un perro, con un caballo, luego con un zorrino operado, que llevó durante un tiempo en su bolsillo" (249).

Es especialmente interesante el hecho de que Antonio use ese trato especial que tiene con los animales justamente para domarlos, para hacerlos sus mascotas y someterlos a sus designios, quitándoles de este modo, la calidad de salvajes.

¿Pueden ser estos elementos los que hayan llevado a Borges, Bioy Casares y Ocampo a considerar este cuento como fantástico? ¿Es posible que la ambigüedad en cuanto a la identidad, cuando se trata de una ambigüedad entre una ascendencia criolla o europea y una indígena sea tan desestabilizadora que los antologadores la percibieran como fantástica?

En este cuento el motivo de la casa no aparece tan claramente presente. Es el cuerpo de Antonio el que contiene tiempos, razas y 
mundos distintos. ¿Es un hombre o es una estatua de bronce? ¿es blanco o es indio? El cuerpo de Antonio lleva el "nosotros" y el "otro", el civilizado y el bárbaro, disolviendo dentro de sus límites la dicotomía fundacional.

En este sentido, el cuento no se puede incluir en la genealogía propuesta más que como ejemplo excéntrico, que tangencialmente ilustra la idea de las identidades silenciadas adquiriendo formas que, en este caso, se interpretan como fantasmas.

\section{Casas y silencios que gritan}

Exceptuando el cuento de Ocampo, los textos aquí discutidos tienen lugar en casas que actualizan el motivo del castillo gótico. Estas casas pueden verse como un intento de contener el presente con un pasado determinado, de homogeneizar tanto el presente como la Historia. Pero dentro de estas casas irrumpe algo que no cuadra, algo que rompe el orden establecido y contenido por sus paredes. En el caso del cuento de Lugones, el personaje del inglés se desdobla en un mono: la civilización y la barbarie forman las dos caras de una misma moneda, y ambas están del lado de adentro.

En el caso de Chiáppori, vimos dos casas. La primera, la del relato marco, en la cual tienen lugar la narración de los relatos enmarcados. Un espacio en el cual la Historia es una historia burguesa que muestra sólo una de las tantas caras que podía llegar a tener la sociedad porteña (del Buenos Aires) del momento, la cara oficial, la cara deseada. Pero éste es un espacio efímero e inaprehensible, el narrador sólo puede ingresar en él durante un otoño y lo que la llamada interlocutora escriba desde ese interior no será leído nunca por nadie.

En "Un libro imposible" nos encontramos con otra casa, la casa de Agusto Caro, una casa que el narrador visita una noche de tormenta y que resiste los embates del viento y la lluvia mientras ellos conversan. Una casa que pesar de erigirse como un trozo de civilización en medio de las fuerzas de la naturaleza, anida fuerzas oscuras en su interior. 
En "Casa tomada", la historia también tiene lugar en una casa que guarda los recuerdos de una familia patricia junto con libros en francés, y otros elementos típicos de un estilo de vida burgués, "civilizado". El hecho fantástico va cerrando a los hermanos la posibilidad de acceder a la "civilización" encerrada en la casa. Los ruidos inexplicables parecen aliarse con el polvo de la cuidad, en unas especie de revuelta de la barbarie contra la civilización. Pero los ruidos, a diferencia del polvo, provienen del interior de la casa, del centro de civilización que ésta representa.

Si bien "La expiación" no puede considerarse un cuento fantástico debido a la falta de hecho insólito y, por ende, a la falta de conflicto entre dos modos epistemológicamente incompatibles de concebir el mundo, es discutido en este trabajo a raíz de su inclusión en la Antología de la literatura fantástica por parte de Borges, Bioy Casares y Ocampo. En este cuento excéntrico para la genealogía aquí propuesta, lo salvaje irrumpe desde dentro de Antonio, cuyo pasado oculto se hace más y más obvio para su mujer quien lo desconocía desde un principio. La ambigüedad de la identidad de Antonio es uno de los temas principales del cuento y parece poseer un poder desestabilizador tal que podría ser la explicación de que el cuento haya sido considerado fantástico por sus antologadores.

Todas estas fuerzas salvajes que irrumpen en el centro mismo de la civilización representado por las casas/castillos, o en un cuerpo conocido en el caso del último cuento, pueden entenderse como fuerzas ominosas. Según Freud lo ominoso, lo Unheimliche, surge al aparecer lo que no es familiar, son el retorno de una realidad reprimida, de aquello que se quiso excluir de la historia y de la Historia. Al irrumpir lo Unheimliche en el centro de estos monumentos civilizatorios, nos deja ver la cara oculta y oscura de la mano de la cual se forjó la "civilización" en la nueva Argentina. El hecho fantástico entonces puede entenderse como la resistencia al silencio de lo silenciado. 


\section{Obras citadas}

Alazraki, Jaime. En busca del unicornio: los cuentos de Julio Cortázar. Elementos para una poética de lo neofantástico. Madrid: Gredos, 1983. Andermann, Jens. "Fronteras: la conquista del desierto y la economía de la violencia." En: Ficciones y silencios fundacionales. Literaturas y culturas poscoloniales en América Latina (siglo XIX). Ed. Friedhelm Schmidt-Welle. Madrid/Frankfurt am Main: Iberoamericana Vervuert, 2003. 117-135.

Anderson, Benedict. Imagined Communities. Reflections on the Origin and Spread of Nationalism. [1983] London, New York: Verso, 1991. Andreu, Jean L. "Pour une lecture de Casa tomada de Julio Cortázar." Caravelle. Cabiers du monde bispanique et lusobrésilien 10 (1968): 49-66. Bajtin, Mijail. "Las formas del tiempo y del cronotopo en la novela." Teoría y estética de la novela. Trabajos de investigación. [1937-38] Trad. Helena S. Kriúkova y Vicente Cazcarra. Madrid: Taurus, 1989. 237-410.

Campra, Rosalba. "Los silencios del texto en la literatura fantástica." En: El relato fantástico en España e Hispanoamérica. Ed. Enriqueta Morillas Ventura. Madrid: Siruela, 1991. 49-73.

Castro, Andrea. El encuentro imposible. La conformación del fantástico ambiguo en la narrativa breve argentina (1862-1910). Göteborg: Acta Universitatis Gothoburgensis, 2002.

Chiáppori, Atilio. Borderland. La eterna angustia. Buenos Aires: Guillermo Kraft, 1954.

Cortázar, Julio [1951]. "Casa tomada." Bestiario. 5a. ed. Buenos Aires: Sudamericana. 1966. 9-18.

Derrida, Jaques. Spectres de Marx. L'État de la dette, le travail du denil et la nouvelle Internationale. Paris: Galilée, 1993.

Freud, Sigmund [1919]. "Lo ominoso." Trad. José L. Etcheverry. En: S. Freud. Obras completas. Tomo XVII. Buenos Aires: Amorrotu editores. 1992. 215-251.

Holmes, Amanda "Residential Unhomes in Short Stories by Julio Cortázar and Ilse Aichinger.” Neophilolugus 87 (2003): 247-264. Hourcade, Eduardo. "La pampa gringa, invención de una sociabili- 
dad europea en el desierto." Historia de la vida privada en la Argentina. La Argentina plural 1870-1930. Tomo II. Eds. Fernando Devoto y Marta Madero. Buenos Aires: Taurus, 1999. 163-187 Jackson, Rosie. Fantasy: the Literature of Subversion. London and New York: Methuen, 1981.

Lobato, Mirta Zaida. "Los trabajadores en la era del progreso." En:

Nueva historia argentina. El progreso, la modernización y sus límites (1880-1916). Tomo V. Dir. Mirta Zaida Lobato. Buenos Aires: Sudamericana, 2000. 465-506.

Lugones, Leopoldo. "Un fenómeno inexplicable." Las fuerzas extrañas. Buenos Aires: Ediciones del 80, 1984. 75-83.

Moreno Turner, Fernando. "El texto en movimiento, movimientos del texto. Nuevo asalto a 'Casa tomada' de Julio Cortázar." Acta literaria 23 (1998): 69-80.

Ocampo, Silvina [1965]. "La expiación." En: Antología de la literatura fantástica. Antologs. Jorge Luis Borges, Adolfo Bioy Casares y Silvina Ocampo. Barcelona: Edhasa, 1981. 246-256.

Pérez Venzalá, Valentín. "Incesto y espacialización del psiquismo en 'Casa tomada' de Cortázar.” Espéculo. Revista de estudios literarios 10 (1998-1999) < http://www.ucm.es/info/especulo/numero10/index.htm >

Perilli, Carmen. Las ratas en la torre de Babel. La novela argentina entre 1982 y 1992. Buenos Aires: Ediciones Letra Buena, 1994.

Planells, Antonio. "“Casa tomada' o la parábola del limbo." Revista Iberoamericana. 52.135-136 (1986): 591-603.

Quijada, Mónica. "Indígenas: violencia, tierras y ciudadanía". En: Homogeneidad y nación con un estudio de caso: Argentina, siglos XIX y XX. Eds. Mónica Quijada, Carmen Bernand y Arnd Schneider. Madrid: Consejo Superior de Investigaciones Científicas, 2000. 57-92.

Rotker, Susana. Cautivas. Olvidos y memoria en la Argentina. Buenos Aires: Ariel, 1999.

Sarmiento, Domingo Faustino [1945] Facundo. Buenos Aires: Kapelusz, 1971.

Sosnowski, Saúl. Julio Cortázar una búsqueda mitica. Buenos Aires: 
Ediciones Noé, 1973.

Viñas, David [1982]. Indios, ejército y frontera. Buenos Aires: Santiago Arcos editor, 2003.

Zeberio, Blanca. "Un mundo rural en cambio." Nueva historia argentina. Liberalismo, estado y orden burgués (1852-1880). Tomo IV. Dir. Marta Bonaudo. Buenos Aires: Sudamericana, 1999. 293-362. 